\title{
A new inflammation index is useful for patients with esophageal squamous cell carcinoma
}

This article was published in the following Dove Press journal:

OncoTargets and Therapy

30 September 2014

Number of times this article has been viewed

\section{Ji-Feng Feng' \\ Ying Huang ${ }^{2}$ \\ Qi Xun Chen'}

'Department of Thoracic Surgery, ${ }^{2}$ Department of Operating Theater, Zhejiang Cancer Hospital, Hangzhou, People's Republic of China
Correspondence: Ji-Feng Feng Department of Thoracic Surgery, Zhejiang Cancer Hospital, 38 Guangji Road, Banshan Bridge, Hangzhou, Zhejiang 310022, People's Republic of China Tel +8657I 88I28062

Email jifzhejiang@gmail.com
Background: The prognostic value of inflammation indexes in esophageal cancer has not been established. Recent studies have shown that the advanced lung cancer inflammation index (ALI) is a useful predictive factor. The purpose of the current study was to determine whether the ALI is useful for predicting long-term survival in patients with esophageal squamous cell carcinoma (ESCC).

Patients and methods: A total of 293 patients who had undergone esophagectomy for ESCC were included. The ALI was calculated as body mass index $\times$ serum albumin/neutrophilto-lymphocyte ratio. Then, patients were divided into two groups: ALI $\geq 18$ and ALI $<18$. The Kaplan-Meier method was used to calculate the cancer-specific survival (CSS), and the difference was assessed by the log-rank test. Univariate and multivariate analyses were performed to evaluate the prognostic factors.

Results: In our study, there were 120 patients with ALI $<18$ and 173 patients with ALI $\geq 18$. ALI was significantly higher in patients with large tumors $(P=0.028)$, poor differentiation $(P=0.010)$, deep invasion $(P=0.009)$, and nodal metastasis $(P=0.004)$. The 5-year CSS was $34.5 \%$ in our study. Patients with ALI $<18$ had a significantly poorer 5-year CSS compared to ALI $\geq 18$ (21.7\% versus $43.4 \%, P<0.001)$. On multivariate analysis, we showed that the ALI was a significant predictive factor of CSS $(P=0.024)$.

Conclusion: The ALI is still a useful predictive factor for long-term CSS in patients with ESCC. However, the prognostic value of the ALI is yet to be formally tested within randomized trials.

Keywords: esophageal squamous cell carcinoma, neutrophil-to-lymphocyte ratio, body mass index, albumin, survival

\section{Introduction}

Esophageal cancer (EC) is the eighth most common cancer worldwide. ${ }^{1}$ In the People's Republic of China, EC was the fourth most frequently diagnosed cancer and the fourth leading cause of cancer death in 2008. ${ }^{1}$ Esophageal squamous cell carcinoma (ESCC) is the most common pathological type of ECs in the People's Republic of China, in contrast to the predominance of esophageal adenocarcinoma in the Western countries. ${ }^{2,3}$ Because there are vital biological differences between ECs in the People's Republic of China and Western countries, a prognostic model that takes into account the predominance of ESCC in the People's Republic of China is necessary for deciding on a postoperative strategy that will prolong the survival. Thus, assessing the prognostic factors in ESCC is more and more important. 
Recently, systemic inflammatory response (SIR) plays a vital role in the progression of cancer. ${ }^{4,5}$ Previous reports have shown that systemic inflammation, indicated by an elevated level of serum C-reactive protein (CRP), strongly influenced the prognosis in patients with gastrointestinal carcinomas. ${ }^{6}$ Moreover, the Glasgow prognostic score (GPS), which is based on the serum CRP and hypoalbuminemia, has been demonstrated as an indicator for the prognosis in various types of cancers, including ECs..$^{7-9}$ In addition, there is increasing evidence that neutrophil to lymphocyte ratio (NLR) can be used for prognostication in several types of cancer. ${ }^{10,11}$ Recently, Jafri et al ${ }^{12}$ evaluated a novel inflammation-based prognostic system, named advanced lung cancer inflammation index (ALI; based on body mass index, serum albumin [Alb] and NLR). The results showed that ALI was considered as a useful predictive factor in lung cancer. ${ }^{12}$ To our knowledge, however, no studies regarding ALI in patients with ECs are available. Therefore, the purpose of the current study was to determine whether the ALI is still useful for predicting long-term survival in patients with ESCC.

\section{Materials and methods}

A retrospective analysis was performed on 293 patients with ESCC in our department from January 2006 to December 2008. All patients were diagnosed as ESCC. Patients who had received preoperative neoadjuvant therapy (chemotherapy and/or radiotherapy) were excluded. Based on the medical records, the following data were collected for each patient: age, sex, height, weight, differentiation, tumor length and location, laboratory examination, depth invasion, nodal metastasis, and other miscellaneous characteristics. Ethical approval was obtained from the Ethical Committees of Zhejiang Cancer Hospital. In our institute, the patients were followed up in the outpatient department. Either X-ray or computed tomography of the chest was performed during the follow-up. The cancer-specific survival (CSS) was analyzed in this study. The last follow-up time was November 2011. All patients were staged according to the 7th edition of the American Joint Committee on Cancer Cancer Staging. ${ }^{13}$

All of the patients were treated with esophagectomy. The standard surgical approach included the Ivor Lewis and the McKeown procedure. ${ }^{2}$ The lymphadenectomy included two-field (thoracoabdominal) and three-field (cervicalthoracoabdominal) lymphadenectomy. Most of the patients underwent two-field lymphadenectomy. Three-field lymphadenectomy was used only if the cervical nodes metastasis.
As the role of postoperative adjuvant chemoradiotherapy was controversial during that period, postoperative adjuvant therapy was not mandatory. Cisplatin and 5-fluorouracil were the most frequent chemotherapy. Postoperative radiation was initially performed through the anteroposterior field to $36 \mathrm{~Gy}$, then through the parallel opposing oblique fields to $14 \mathrm{~Gy}$, in order to avoid the spinal cord.

\section{Statistical analysis}

Statistical analysis was conducted with SPSS 17.0 (SPSS Inc., Chicago, IL, USA). The ALI was calculated using the following formula: body mass index $(\mathrm{BMI}) \times \mathrm{Alb} / \mathrm{NLR}$, and it was categorized into two groups: (ALI $\geq 18$ and ALI $<18$ ). ${ }^{12}$ The BMI $=$ body weight $(\mathrm{kg}) /$ height $^{2}\left(\mathrm{~m}^{2}\right)$, and it was categorized into two groups: $\left(\mathrm{BMI}>18.5 \mathrm{~kg} / \mathrm{m}^{2}\right.$ and $\left.\mathrm{BMI} \leq 18.5 \mathrm{~kg} / \mathrm{m}^{2}\right) .{ }^{14}$ The Alb was categorized into two groups: (Alb $>3.5 \mathrm{~g} / \mathrm{dL}$ and $\mathrm{Alb} \leq 3.5 \mathrm{~g} / \mathrm{dL}) .{ }^{15}$ The NLR was categorized into two groups: (NLR $<5$ and NLR $\geq 5) .{ }^{10,11}$ The Kaplan-Meier method was used to calculate the CSS, and the difference was assessed by the log-rank test. Univariate and multivariate analyses were performed to evaluate the prognostic factors. A $P<0.05$ was considered to be statistically significant.

\section{Results}

Among the 293 patients, there were 34 (11.6\%) women and $259(88.4 \%)$ men. The mean age was $59.5 \pm 7.9$ years (range from 38 to 78 years). There were 120 (41.0\%) patients with ALI $<18$, and 173 (59.0\%) patients with ALI $\geq 18$.

The relationships between the ALI and clinicopathological characteristics of the 293 patients for ESCC are shown in Table 1. Our study showed that ALI was significantly higher in patients with large tumors $(P=0.028)$, poor differentiation $(P=0.010)$, deep invasion $(P=0.009)$, and nodal metastasis $(P=0.004)$.

The 5-year CSS was $34.5 \%$ in our study. Patients with ALI $<18$ had a significantly poor 5 -year CSS compared to ALI $\geq 18$ (21.7\% versus $43.4 \%, P<0.001)$ (Figure 1). By univariate analysis, tumor length, vessel involvement, depth invasion, nodal metastasis, BMI, Alb, NLR, and ALI were significant association with the 5-year CSS. On multivariate analysis, we showed that ALI was a significant predictive factor of CSS $(P=0.024)$ (Table 2).

\section{Discussion}

To our knowledge, this is the first study to show ALI as an independent prognostic factor in patients with ESCC. Our study demonstrated that ALI is still a useful predictive factor for CSS in patients who underwent esophagectomy for ESCC. 
Table I The relationship between ALI and clinicopathological characteristics

\begin{tabular}{|c|c|c|c|c|}
\hline & $\begin{array}{l}\text { Cases } \\
(n, \%)\end{array}$ & $\begin{array}{l}\text { ALI }<\text { I8 } \\
(n, \%)\end{array}$ & $\begin{array}{l}\text { ALI } \geq 18 \\
(n, \%)\end{array}$ & $P$-value \\
\hline Age (years) & & & & 0.483 \\
\hline$\leq 60$ & I6I (54.9) & $63(52.5)$ & $98(56.6)$ & \\
\hline$>60$ & $132(45.1)$ & $57(47.5)$ & $75(43.4)$ & \\
\hline Sex & & & & 0.475 \\
\hline Female & $34(1 \mathrm{I} .6)$ & $12(10.0)$ & $22(12.7)$ & \\
\hline Male & $259(88.4)$ & $108(90.0)$ & $151(87.3)$ & \\
\hline Tumor length $(\mathrm{cm})$ & & & & 0.028 \\
\hline$\leq 3$ & $76(25.9)$ & $23(19.2)$ & $53(30.6)$ & \\
\hline$>3$ & $217(74.1)$ & $97(80.8)$ & $120(69.4)$ & \\
\hline Tumor location & & & & 0.304 \\
\hline Upper & $16(5.5)$ & $5(4.2)$ & II (6.4) & \\
\hline Middle & I $43(48.8)$ & $54(45.0)$ & $89(51.4)$ & \\
\hline Lower & $134(45.7)$ & $61(50.8)$ & $73(42.2)$ & \\
\hline Differentiation & & & & 0.010 \\
\hline Well & $43(14.7)$ & II (9.2) & $32(18.5)$ & \\
\hline Moderate & $188(64.2)$ & $75(62.5)$ & $113(65.3)$ & \\
\hline Poor & $62(21.1)$ & $34(28.3)$ & $28(16.2)$ & \\
\hline Vessel involvement & & & & 0.808 \\
\hline Negative & $246(84.0)$ & $100(83.3)$ & I $46(84.4)$ & \\
\hline Positive & $47(16.0)$ & $20(16.7)$ & $27(15.6)$ & \\
\hline Depth invasion & & & & 0.009 \\
\hline $\mathrm{TI}$ & $49(16.7)$ & $13(10.8)$ & $36(20.8)$ & \\
\hline $\mathrm{T} 2$ & $46(15.7)$ & $17(14.2)$ & $29(16.8)$ & \\
\hline T3 & $163(55.6)$ & $68(56.7)$ & $95(54.9)$ & \\
\hline $\mathrm{T} 4 \mathrm{a}$ & $35(12.0)$ & $22(18.3)$ & $13(7.5)$ & \\
\hline Nodal metastasis & & & & 0.004 \\
\hline Negative & 149 (50.9) & $49(40.8)$ & $100(57.8)$ & \\
\hline Positive & 144 (49.1) & 71 (59.2) & $73(42.2)$ & \\
\hline Adjuvant therapy & & & & 0.010 \\
\hline No & $196(66.9)$ & $70(58.3)$ & $127(73.4)$ & \\
\hline Yes & $97(33.1)$ & $50(4 I .7)$ & $47(26.6)$ & \\
\hline
\end{tabular}

Note: Statistically significant P-values are shown in bold.

Abbreviation: ALI, advanced lung cancer inflammation index.

ALI $<18$ had a hazard ratio (HR) of 1.433 (95\% confidence interval $[\mathrm{CI}]: 1.048-1.959 ; P=0.024)$ for CSS. In our study, we analyze the potential prognostic role of ALI in ESCC patients without neoadjuvant chemoradiotherapy, mainly because chemotherapy or radiation will have an important impact on the systemic inflammation.

BMI is a steady nutritional indicator. BMI levels may vary between healthy and diseased conditions or obese and non-obese persons or even healthy condition and malnutrition. Thus, the importance of BMI with regard to cancer progression can have different implications. Previous published studies have shown that BMI is a predictor of survival in several cancers, such as breast cancer, gynecologic cancer, and lymphoma. ${ }^{16-18}$ However, due to the inconsistent results, its role in EC is still controversial. Engeland et $\mathrm{al}^{14}$ reported that low BMI increased the risk of ESCC. However,

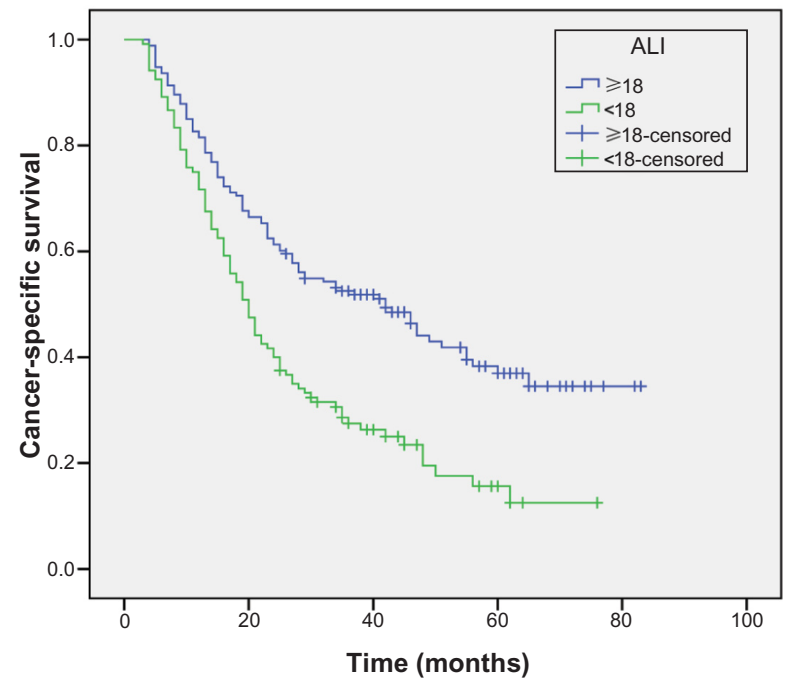

Figure I Patients with ALI $<18$ had a significantly poor 5 -year cancer-specific survival compared to $A L I \geq I 8$ ( $21.7 \%$ versus $43.4 \%, P<0.001)$.

Abbreviation: $A L I$, advanced lung cancer inflammation index.

Skipworth et al ${ }^{19}$ demonstrated that BMI did not demonstrate as an independent predictive factor of survival in EC patients undergoing radical esophagectomy. Grotenhuis et $\mathrm{al}^{20}$ also showed that BMI did not have prognostic role for short- or long-term survival in EC patients. In our study, although BMI was not a significant predictor in patients with ESCC, patients with BMI $\leq 18.5 \mathrm{~kg} / \mathrm{m}^{2}$ had a significantly poor 5-year CSS compared to BMI $>18.5 \mathrm{~kg} / \mathrm{m}^{2}$ (24.5\% versus $40.4 \%, P<0.001)$.

It has been reported that Alb participate in the SIR. Hypoalbuminemia is a useful prognostic factor for survival in patients with various cancers. Uppal et $\mathrm{al}^{21}$ reported that preoperative hypoalbuminemia is an independent predictor of poor outcomes in gynecologic cancers. Chandrasinghe et $\mathrm{al}^{22}$ also showed that hypoalbuminemia predicts poor survival in patients with rectal cancer. In ECs, Ikeda et $\mathrm{al}^{23}$ demonstrated that hypoalbuminemia was significantly associated with poor survival in EC patients. In addition, recent studies reported that hypoalbuminemia was predictive of the response to adjuvant chemoradiotherapy for EC..$^{24,25} \mathrm{In}$ our study, however, hypoalbuminemia was not a significant predictor in patients with ESCC.

NLR is another prognostic factor for survival in various cancers, such as lung cancer, colorectal cancer, and urinary cancer. ${ }^{26,27}$ However, its role in EC is still controversial. Sharaiha et $\mathrm{al}^{10}$ and Sato et $\mathrm{al}^{11}$ reported that NLR $>5$ correlated with poor survival in EC patients. However, Rashid et $\mathrm{al}^{28}$ and Dutta et $\mathrm{al}^{29}$ revealed that NLR did not associate with survival in patients with EC. In our study, however, we have demonstrated that BMI, Alb, and NLR did not have prognostic value for patients 
Table 2 Univariate and multivariate analyses of CSS in ESCC patients

\begin{tabular}{|c|c|c|c|c|c|}
\hline & CSS (\%) & Chi-square & $P$-value & HR (95\% CI) & $P$-value \\
\hline Age (years) & & 0.005 & 0.940 & - & - \\
\hline$\leq 60$ & 33.5 & & & & \\
\hline$>60$ & 35.6 & & & & \\
\hline Sex & & 0.001 & 0.980 & - & - \\
\hline Female & 35.3 & & & & \\
\hline Male & 34.4 & & & & \\
\hline Tumor length $(\mathrm{cm})$ & & 17.494 & $<0.001$ & & 0.219 \\
\hline$\leq 3$ & 52.6 & & & 1.000 & \\
\hline$>3$ & 28.1 & & & $1.294(0.858-1.952)$ & \\
\hline Tumor location & & 0.548 & 0.459 & - & - \\
\hline Upper/middle & 37.1 & & & & \\
\hline Lower & 31.3 & & & & \\
\hline Differentiation & & 2.781 & 0.095 & - & - \\
\hline Well/moderate & 35.8 & & & & \\
\hline Poor & 29.5 & & & & \\
\hline Vessel involvement & & 8.543 & 0.003 & & 0.395 \\
\hline Negative & 37.4 & & & 1.000 & \\
\hline Positive & 19.1 & & & I.I 74 (0.8II-I.70I) & \\
\hline Depth invasion & & 24.961 & $<\mathbf{0 . 0 0 I}$ & & 0.036 \\
\hline $\mathrm{TI}-2$ & 56.5 & & & 1.000 & \\
\hline T3-4a & 24.4 & & & I.527 (I.027-2.27I) & \\
\hline Nodal metastasis & & 54.063 & $<\mathbf{0 . 0 0 1}$ & & $<\mathbf{0 . 0 0 1}$ \\
\hline Negative & 53.0 & & & 1.000 & \\
\hline Positive & 15.3 & & & $2.101(1.507-2.930)$ & \\
\hline Adjuvant therapy & & 0.100 & 0.752 & - & - \\
\hline No & 36.7 & & & & \\
\hline Yes & 29.9 & & & & \\
\hline Alb $(g / d L)$ & & 23.484 & $<\mathbf{0 . 0 0 I}$ & & 0.160 \\
\hline$>3.5$ & 40.4 & & & 1.000 & \\
\hline$\leq 3.5$ & 15.7 & & & $1.285(0.905-1.824)$ & \\
\hline BMI $\left(\mathrm{kg} / \mathrm{m}^{2}\right)$ & & 10.370 & 0.001 & & $0.74 I$ \\
\hline$>18.5$ & 40.4 & & & 1.000 & \\
\hline$\leq 18.5$ & 24.5 & & & $\mathrm{I} .060(0.752-1.494)$ & \\
\hline NLR & & II.407 & 0.001 & & 0.096 \\
\hline$<5$ & 38.2 & & & 1.000 & \\
\hline$\geq 5$ & 10.3 & & & $1.436(0.938-2.198)$ & \\
\hline$A L I$ & & 19.847 & $<\mathbf{0 . 0 0 1}$ & & 0.024 \\
\hline$\geq 18$ & 43.4 & & & 1.000 & \\
\hline$<18$ & 21.7 & & & I.433 (I.048-1.959) & \\
\hline
\end{tabular}

Note: Statistically significant P-values are shown in bold.

Abbreviations: CSS, cancer-specific survival; ESCC, esophageal squamous cell carcinoma; NLR, neutrophil to lymphocyte ratio; Alb, serum albumin; BMI, body mass index; $\mathrm{ALI}$, advanced lung cancer inflammation index; $\mathrm{Cl}$, confidence interval; $\mathrm{HR}$, hazard ratio.

with ESCC. Thus, we used a new inflammation index, named ALI, based on BMI, Alb and NLR. Our study demonstrated that ALI was a significant predictive factor of $\operatorname{CSS}(P=0.024)$.

In conclusion, ALI is still a useful predictive factor in patients with ESCC. ALI is an easy method to assess the systemic inflammation in ESCC patients. High systemic inflammation as judged by ALI $<18$ had a significantly poor 5 -year CSS compared to ALI $\geq 18$. However, the prognostic value of the ALI remains to be formally tested within the randomized trials.

\section{Disclosure}

The authors report no conflicts of interest in this work.

\section{References}

1. Ferlay J, Shin HR, Bray F, Forman D, Mathers C, Parkin DM. Estimates of worldwide burden of cancer in 2008: GLOBOCAN 2008. Int J Cancer. 2010;127(12):2893-2917.

2. Tachibana M1, Kinugasa S, Hirahara N, Yoshimura H. Lymph node classification of esophageal squamous cell carcinoma and adenocarcinoma. Eur J Cardiothorac Surg. 2008;34(2):427-431.

3. Lindkvist B, Johansen D, Stocks T, et al. Metabolic risk factors for esophageal squamous cell carcinoma and adenocarcinoma: a prospective study of 580,000 subjects within the Me-Can project. BMC Cancer. 2014;14:103. 
4. Mantovani A, Allavena P, Sica A, Balkwill F. Cancer-related inflammation. Nature. 2008;454(7203):436-444.

5. Balkwill F, Mantovani A. Inflammation and cancer: back to Virchow? Lancet. 2001;357(9255):539-545.

6. Crumley AB, McMillan DC, McKernan M, Going JJ, Shearer CJ, Stuart RC. An elevated C-reactive protein concentration, prior to surgery, predicts poor cancer-specific survival in patients undergoing resection for gastro-oesophageal cancer. Br J Cancer. 2006;94(11):1568-1571.

7. McMillan DC, Crozier JE, Canna K, Angerson WJ, McArdle CS. Evaluation of an inflammation-based prognostic score (GPS) in patients undergoing resection for colon and rectal cancer. Int J Colorectal Dis. 2007;22(8):881-886.

8. Vashist YK, Loos J, Dedow J, et al. Glasgow Prognostic Score is a predictor of perioperative and long-term outcome in patients with only surgically treated esophageal cancer. Ann Surg Oncol. 2011;18(4):1130-1138.

9. Polterauer S, Grimm C, Seebacher V, et al. The inflammation-based Glasgow Prognostic Score predicts survival in patients with cervical cancer. Int J Gynecol Cancer. 2010;20(6):1052-1057.

10. Sharaiha RZ, Halazun KJ, Mirza F, et al. Elevated preoperative neutrophil:lymphocyte ratio as a predictor of postoperative disease recurrence in esophageal cancer. Ann Surg Oncol. 2011;18(12):3362-3369.

11. Sato H, Tsubosa Y, Kawano T. Correlation between the pretherapeutic neutrophil to lymphocyte ratio and the pathologic response to neoadjuvant chemotherapy in patients with advanced esophageal cancer. World J Surg. 2012;36(3):617-622.

12. Jafri SH, Shi R, Mills G. Advance lung cancer inflammation index (ALI) at diagnosis is a prognostic marker in patients with metastatic non-small cell lung cancer (NSCLC): a retrospective review. $B M C$ Cancer. 2013;13:158.

13. Rice TW, Rusch VW, Ishwaran H, Blackstone EH. Cancer of the esophagus and esophagogastric junction: data-driven staging for the seventh edition of the American Joint Committee on Cancer/International Union Against Cancer Staging manuals. Cancer. 2010;116(16):3763-3773.

14. Engeland A, Tretli S, Bjørge T. Height and body mass index in relation to esophageal cancer: 23-year follow-up of two million Norwegian men and women. Cancer Causes Control. 2004;15(8):837-843.

15. Ishizuka M, Nagata H, Takagi K, Kubota K. Influence of inflammationbased prognostic score on mortality of patients undergoing chemotherapy for far advanced or recurrent unresectable colorectal cancer. Ann Surg. 2009;250(2):268-272.

16. Kawai M, Minami Y, Nishino Y, Fukamachi K, Ohuchi N, Kakugawa Y. Body mass index and survival after breast cancer diagnosis in Japanese women. BMC Cancer. 2012;12:149.
17. Gates EJ, Hirschfield L, Matthews RP, Yap OW. Body mass index as a prognostic factor in endometrioid adenocarcinoma of the endometrium. J Natl Med Assoc. 2006;98(11):1814-1822.

18. Weiss $\mathrm{L}$, Melchardt T, Habringer $\mathrm{S}$, et al. Increased body mass index is associated with improved overall survival in diffuse large B-cell lymphoma. Ann Oncol. 2014;25(1):171-176.

19. Skipworth J, Foster J, Raptis D, Hughes F. The effect of preoperative weight loss and body mass index on postoperative outcome in patients with esophagogastric carcinoma. Dis Esophagus. 2009;22(7):559-563.

20. Grotenhuis BA, Wijnhoven BP, Hötte GJ, van der Stok EP, Tilanus HW, van Lanschot JJ. Prognostic value of body mass index on short-term and long-term outcome after resection of esophageal cancer. World $J$ Surg. 2010;34(11):2621-2627.

21. Uppal S, Al-Niaimi A, Rice LW, et al. Preoperative hypoalbuminemia is an independent predictor of poor perioperative outcomes in women undergoing open surgery for gynecologic malignancies. Gynecol Oncol. 2013;131(2):416-422

22. Chandrasinghe PC, Ediriweera DS, Kumarage SK, Deen KI. Preoperative hypoalbuminaemia predicts poor overall survival in rectal cancer: a retrospective cohort analysis. BMC Clin Pathol. 2013;13:12.

23. Ikeda M, Natsugoe S, Ueno S, Baba M, Aikou T. Significant hostand tumor-related factors for predicting prognosis in patients with esophageal carcinoma. Ann Surg. 2003;238(2):197-202.

24. Wang CY, Hsieh MJ, Chiu YC, et al. Higher serum C-reactive protein concentration and hypoalbuminemia are poor prognostic indicators in patients with esophageal cancer undergoing radiotherapy. Radiother Oncol. 2009;92(2):270-275.

25. Di Fiore F, Lecleire S, Pop D, et al. Baseline nutritional status is predictive of response to treatment and survival in patients treated by definitive chemoradiotherapy for a locally advanced esophageal cancer. $\mathrm{Am} \mathrm{J}$ Gastroenterol. 2007;102(11):2557-2563.

26. Cedrés S, Torrejon D, Martínez A, et al. Neutrophil to lymphocyte ratio (NLR) as an indicator of poor prognosis in stage IV non-small cell lung cancer. Clin Transl Oncol. 2012;14(11):864-869.

27. Proctor MJ, McMillan DC, Morrison DS, et al. A derived neutrophil to lymphocyte ratio predicts survival in patients with cancer. $\mathrm{Br}$ J Cancer. 2012;107(4):695-699.

28. Rashid F, Waraich N, Bhatti I, et al. A pre-operative elevated neutrophil:lymphocyte ratio does not predict survival from oesophageal cancer resection. World J Surg Oncol. 2010;8:1.

29. Dutta S, Crumley AB, Fullarton GM, et al. Comparison of the prognostic value of tumour- and patient-related factors in patients undergoing potentially curative resection of oesophageal cancer. World J Surg. 2011;35(8):1861-1866
OncoTargets and Therapy

\section{Publish your work in this journal}

OncoTargets and Therapy is an international, peer-reviewed, open access journal focusing on the pathological basis of all cancers, potential targets for therapy and treatment protocols employed to improve the management of cancer patients. The journal also focuses on the impact of management programs and new therapeutic agents and protocols on

\section{Dovepress}

patient perspectives such as quality of life, adherence and satisfaction. The manuscript management system is completely online and includes a very quick and fair peer-review system, which is all easy to use. Visit http://www.dovepress.com/testimonials.php to read real quotes from published authors. 